\title{
Investigation on hole quality of cutting conditions in drilling of CFRP composite
}

\author{
Nafiz Yaşar ${ }^{1, *}$, Mehmet Erdi Korkmaz ${ }^{2}$, and Mustafa Günay ${ }^{2}$ \\ ${ }^{1}$ Karabük University, TOBB Vocational School, Bilimler Meslek Yüksekokulu, Demir Çelik \\ Kampüsü, 78050, Karabük, Turkey \\ ${ }^{2}$ Karabük University, Department of Mechanical Engineering, Balıklarkayası, Mevkii, 78050, \\ Karabük, Turkey
}

\begin{abstract}
Surface damages and delamination occurred in drilling of the carbon fiber reinforced polymer composite materials, which change depending on their physical and mechanical properties and cutting conditions, and so affect the hole quality. Therefore, it is requires to be selective with regards to drill geometry and drilling parameters during drilling of CFRP. This study investigated the effects of cutting parameters and drill geometry on the hole quality in terms of hole diameter and surface roughness during the drilling of CFRP composite laminate. Drilling experiments were performed with three different levels of drilling parameters that are point angle, cutting speed and feed rate. At the end of the drilling tests, it has determined that if the feed rate increases, the surface roughness value increases while the hole diameter decreases. The feed rate was determined as the most important parameter with a PCR of $78.02 \%$ according to analysis of variance. The better hole quality was obtained with $130^{\circ}$ drill among the three drill geometry.
\end{abstract}

\section{Introduction}

Beyond aerospace, automotive, marine and sport industry [1], the demand for composite materials in implant and its prosthesis parts, manufacturing of chemical, biological and electronic equipment is gradually increasing [2]. CFRP and CFRP composite materials having much more advantages than other materials are preferred and qualified with their excellent properties such as long life, lightness, high strength and corrosion resistance [3]. (Fiber reinforced polymer) FRP materials may display different mechanical properties depending on location of fiber in epoxy matrix. Fiber reinforcements and polymer matrix are existed within FRP materials [4]. Their mechanical properties may be different according to location of fiber in epoxy matrix [5]. Fiber reinforced polymer (FRP) composite materials are usually manufactured in geometry of final form in order to provide excellent assembly performance. Therefore, metal removal processes like milling, drilling etc. are needed to meet the requirements of quality and dimension in assembly [6]. For example, structural weight of above $50 \%$ of Boeing 787 airplane is of composite materials and about 55000 drilling processes are performed in manufacturing of structural

\footnotetext{
* Corresponding author: nafizyasar@karabuk.edu.tr
} 
components in airplane $[7,8]$. Thus, drilling is a very common process applied to carbon fiber reinforced polymers (CFRP) [9].

Machinability of FRP composites are harder than conventional metal cutting processes [4] due to poor machinability of fiber reinforced polymer (FRP) laminates usually presenting heterogenic characteristic, anisotropic structure and brittle behavior [10]. Therefore, it requires more attention for selection of cutting tool (tool material, coating type and tool geometry) and cutting parameters (feed rate and cutting speed) when machinability of CFRP composite materials become current issue $[9,11]$. Moreover, delamination that is defined as layer segregation in entry and exit of hole is the most common problem in drilling of composites [12].

Merino-Perez et. al presented the influence of the material properties and the effect of the cutting speed variation on the heat dissipation in the drilling of the studied CFRP composites with SEM analysis. They determined that high cutting speeds caused more severe matrix cracking and hole entry/exit splintering than low cutting speeds. They also suggested using of temperatures not exceeding the decomposition temperature of the matrix within the machining time [13]. Mohan et. al stated that the most important parameters in drilling of GFRP composites are cutting speed and material thickness for entry delamination, feed rate and material thickness for exit delamination according to their experimental and numerical studies [14]. On the other hand, it was emphasized that delamination factor $(\mathrm{Fd})$ is proportional with cutting speed and feed rate, similarly remarked that delamination increases with carbide drills having high point of angles [15]. SenthilKumar et. al emphasized that less progressive tool wear and better chip evacuation was achievable with larger point angle drills in their study of optimizing cutting parameters with genetic algorithm [16]. El-Sonbaty et al. determined that cutting speed has negligible effect on thrust force $(F z)$, but torque values increase with increasing cutting speed [17]. İşbilir ve Ghassemieh indicated that average surface roughness value increase with increasing feed rate while it decreases with increasing cutting speed [18]. It was reported that anisotropic CFRP composites exhibit different machinability characteristics according to different fiber directions during drilling. It is emphasized that various surface defects like resin loss, remove from fiber and matrix degradation may arise on hole surface, causing irregular surface forms [19].

Literature mentioned that CFRP materials are generally machined in dry cutting conditions due to the fact that their dehumidifying properties effect shear fatigue toughness negatively. In this study, the effects of cutting parameters (drill point angle, cutting speed and feed rate) on machinability criteria ( $\mathrm{Ra}$ and Diameter) under dry cutting condition have been investigated experimentally and statistically in drilling of CFRP composites.

\section{Material and method}

As the workpiece material, for drilling, carbon fiber reinforced polymer laminate (CFRP) are used which are produced by vacuum bagging method, laying $245 \mathrm{~g} / \mathrm{m}^{2} 2 \times 2-3 \mathrm{~K}$ structured carbon fiber and prepregs containing Huntsman XU3508 resin to a glass surface symmetrically with suitable fiber angles. In this material, twill textured carbon fibers form with directions of $0^{\circ}$ and $90^{\circ}$ angles. Therefore, only laying angles of $0^{\circ}$ and $45^{\circ}$ are used in production. Reinforcement materials are used 40 times for $10 \mathrm{~mm}$ laminate and the sides of the laminates are vacuumed by bagging with vacuum equipment. Reinforcements compressed by vacuum were placed into furnace and a temperature of $120^{\circ} \mathrm{C}$ was applied to the system by four hours.

Drilling experiments were performed in CNC vertical machining center (Johnford VMC-550) with three various levels of point angle, cutting speed and feed rate in dry machining conditions. Karcan branded tungsten carbide (WC) drills were used as cutting 
tools. Drills have a diameter of $5 \mathrm{~mm}$, helical angle of $30^{\circ}$ and geometry of two cutting edges. Feed rate (f), cutting speed $(\mathrm{V})$ and drill point angle $(\varphi)$ were chosen as factors to apply full factorial experimental design in drilling of CFRP. The levels of these factors were determined by considering tool manufacturer's recommendations and studies on drilling of CFRP composites in literature. Drilling parameters with levels are given in Table 1.

Table 1. Drilling factors and levels.

\begin{tabular}{|c|c|}
\hline Factors & Levels \\
\hline Point Angle $\mathbf{P}\left(^{\circ}\right)$ & $120-130-140$ \\
\hline Cutting Speed V $(\mathrm{m} / \mathrm{min})$ & $60-100-140$ \\
\hline Feed Rate $\mathrm{f}(\mathrm{mm} / \mathrm{rev})$ & $0.05-0.1-0.15$ \\
\hline
\end{tabular}

Drilling processes were repeated as three times and evaluations were done by taking arithmetic averages of machinability criteria ( $\mathrm{Ra}$ and Diameter). Measurements of diameters (D) were performed in 5 points (Figure 1a) from entry, middle and exit of the hole. Hexagon Global Performance device was used in measuring of hole diameters. Surface roughness on hole surfaces were measured with portative Mahr Perthometer M300 device. Three surface roughness measurements were applied for each hole surfaces with a cut-off length of $0.25 \mathrm{~mm}$ and sampling length of $1.75 \mathrm{~mm}$ according to ISO 4288 standard. The arithmetic average of surface roughness values were calculated and evaluations were performed with regards to average surface roughness $(R a)$ value.

In the light of experimental results, the effects of factors on $\mathrm{Ra}$ and $\mathrm{D}$ were determined by analysis of variance (ANOVA) with $95 \%$ confidence level. Since the spindle speed of the CNC milling machine used in the experiments is insufficient, suitable spindle speeds matching the appropriate cutting speeds were obtained using spindle speeder. The experimental setup for drilling experiments (b) and drill geometry (c) were given in Figure 1.

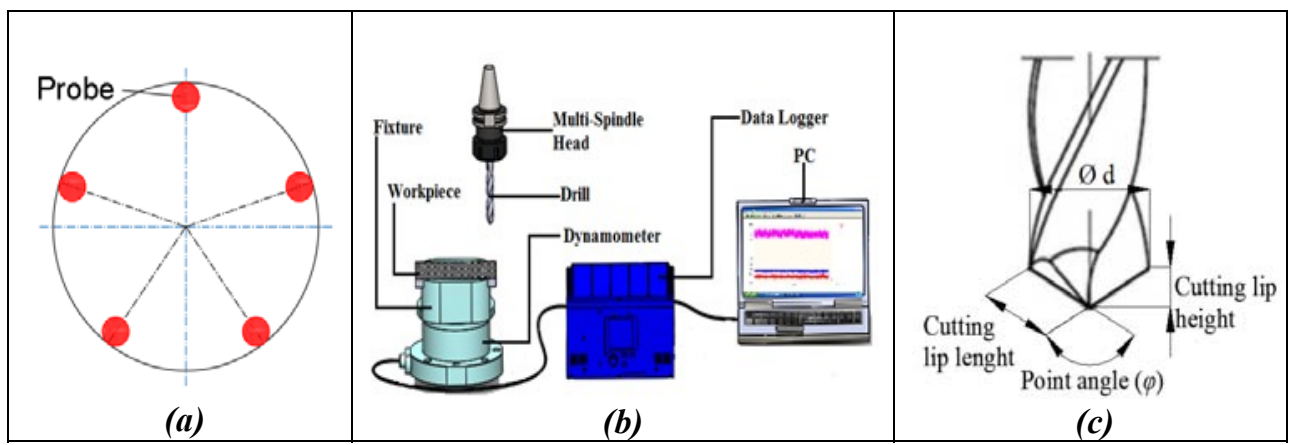

Fig. 1. Experimental setup and drill geometry.

\section{Results and discussion}

The variations of surface roughness (Ra) and diameter (D) in drilling of CFRP with different cutting parameters were given in Figure 2 and Figure 3.

\subsection{Analysis of surface roughness (Ra)}

Surface roughness is one of the surface integrity criteria for all parts manufactured by machining and also is a parameter to be considered in the analysis of the hole quality in 
CFRP drilling. In this study, variation of average surface roughness (Ra) occurred in drilling of CFRP according to drill point angle and drilling parameters is given in Figure 2.

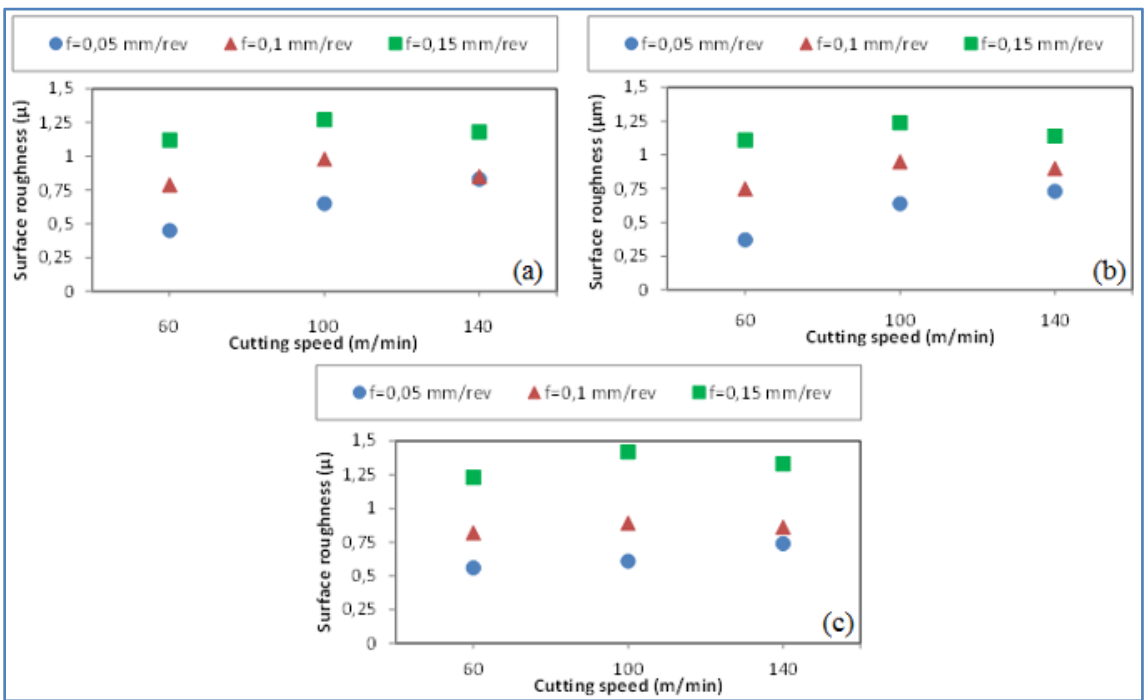

Fig. 2. Variation of surface roughness; point angle of a) $120^{\circ}$, b) $130^{\circ}$, c) 140 .

Examining Figure 3, similar tendencies for average surface roughness ( $\mathrm{Ra}$ ) are observed for each drill point angle. Surface roughness values obtained in drilling process increase with increasing feed rate and cutting speed. It is generally known that surface roughness increases with increasing feed rate. This result is similar with literature [18]. On the other hand, increasing surface roughness values can be explained with increasing thrust force by increasing feed rate [20]. This increase can be referred to increasing chip cross-section area by increasing feed rate. Moreover, it is possible to say that drill cannot perform better due to adhesion on it in higher feed rates [15] and this situation effects increasing surface roughness.

It is understood from the Figure 3 that variation of surface roughness according to drilling parameters with increasing cutting speed. Surface roughness increases with increasing cutting speed from $60 \mathrm{~m} / \mathrm{min}$ to $100 \mathrm{~m} / \mathrm{min}$, subsequently, roughness tends to

Table 2. ANOVA results for surface roughness

\begin{tabular}{|l|l|l|l|l|l|l|}
\hline Factor & DF & SS & MS & F & P & \%PCR \\
\hline$\Phi\left(^{\circ}\right)$ & 2 & 2.382 & 1.191 & 2.74 & 0.124 & 1.1 \\
\hline $\mathrm{V}(\mathrm{m} / \mathrm{min})$ & 2 & 21.807 & 10.904 & 25.1 & 0.000 & 10.05 \\
\hline $\mathrm{f}(\mathrm{mm} / \mathrm{rev})$ & 2 & 169.404 & 84.702 & 194.99 & 0.000 & 78.02 \\
\hline$\varphi^{*} \mathrm{~V}$ & 4 & 2.564 & 0.6409 & 1.48 & 0.296 & 1.18 \\
\hline$\varphi^{*} \mathrm{f}$ & 4 & 2.052 & 0.5129 & 1.18 & 0.388 & 0.95 \\
\hline $\mathrm{V}^{*} \mathrm{f}$ & 4 & 15.426 & 3.8565 & 8.88 & 0.005 & 7.10 \\
\hline Error & 8 & 3.475 & 0.4344 & & & 1.6 \\
\hline Total & 26 & 217.109 & & & & 100 \\
\hline $\mathrm{R}^{2}=98.4 \%$ & \multicolumn{7}{l}{} \\
\hline
\end{tabular}

decrease. As mentioned in recent studies [13], this is mostly originated from the incomplete cutting of fibers and their removal from the matrix with the increasing cutting speed and/or 
the surface defects on drilled hole that occur as a result of matrix-fiber debonding. Surface roughness decreased 6-8\% in cutting speed of $140 \mathrm{~m} / \mathrm{min}$. This result can be referred to the probable remaining of the hole surface temperature below the glass transition temperature of matrix material as a result of decreasing cutting time with high cutting speed.

The lowest $\mathrm{Ra}$ was measured as $0.37 \mu \mathrm{m}$ with drill point angle of $130^{\circ}$, feed rate of 0.05 $\mathrm{mm} / \mathrm{rev}$ and cutting speed of $60 \mathrm{~m} / \mathrm{min}$. The highest Ra value was obtained as $1.42 \mu \mathrm{m}$ in drill point angle of $140^{\circ}$, feed rate of $0.15 \mathrm{~mm} / \mathrm{rev}$ and cutting speed of $100 \mathrm{~m} / \mathrm{min}$. Analysis of variance (ANOVA) was performed to determine the effects of drilling parameters and drill point angle on $\mathrm{Ra}$ that is a significant factor for performance life of structural part manufactured from CFRP (Table 2). As seen in the ANOVA table, the most important drilling parameter that effects the surface roughness is feed rate with a PCR of $78.02 \%$. The other statistically significant parameters over Ra are cutting speed (V) with PCR of $10.05 \%, 7.10 \%$ and $1.18 \%$, interaction between point angle $(\varphi)$ and point anglefeed rate $(\varphi * f)$ respectively.

\subsection{Hole size}

Another significant factor taken into account in determining the hole quality is the hole size. Especially, the need to drilling in desired tolerance with low roughness and suitable roundness due to necessity of high strength in assembly parts is an important safety problem in aerospace industry [10]. In this study, variation of hole diameter values occurred in drilling of CFRP according to point angle and drilling parameters was given in Figure 3.

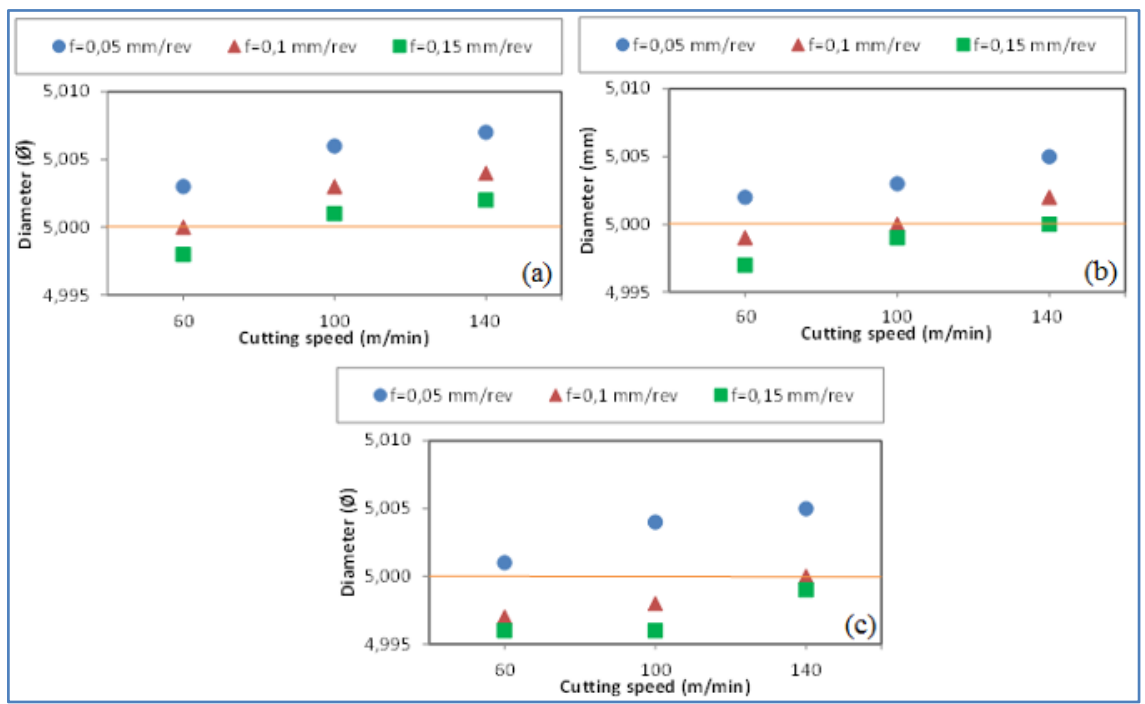

Fig. 3. Variation of hole diameter; drill point angle of a) $120^{\circ}$, b) $130^{\circ}$, c) $140^{\circ}$.

As seen from Figure 4, the hole diameters decreased with increasing of feed rate for all drill point angle. The main reason of higher hole size than nominal value can be explained with cutting temperature varying according to feed rate and cutting speed. It is generally known that the cutting temperature increases with lower feed conditions due to the low thermal conductivity of CFRP [21]. It is generally known that increasing cutting speed leads to increase in vibration [22]. This situation explains the increase in hole diameters with increasing cutting speed. On the other hand, the highest hole size was measured as $5.07 \mathrm{~mm}$ in drill point angle of 120 , cutting speed of $140 \mathrm{~m} / \mathrm{min}$ and feed rate of 0.05 $\mathrm{mm} / \mathrm{rev}$. The lowest hole size was measured as $4.996 \mathrm{~mm}$ in drill point angle of 140, cutting 
speed of $60 \mathrm{~m} / \mathrm{min}$ and feed rate of $0.15 \mathrm{~mm} / \mathrm{rev}$. This result can be explained with decreasing in tool-chip contact area due to increasing drill point angle. Decreasing in cutting lip length and height with increasing drill point angle (see Figure 1.c) will lead to reduce of friction through tool-chip interface, which decreases generated heat, thereby result in CFRP hole sizes closer to the drill diameter.

\section{Conclusion}

In this study, the effects of drill point angle, cutting speed and feed rate on machinability factors ( $\mathrm{Ra}, \mathrm{D})$ when drilling of CFRP composites with uncoated WC drill bits were experimentally and statistically analyzed.

The lowest Ra was measured as $0.37 \mu \mathrm{m}$ with drill point angle of $130^{\circ}$, feed rate of 0.05 $\mathrm{mm} / \mathrm{rev}$ and cutting speed of $60 \mathrm{~m} / \mathrm{min}$. The highest Ra value was obtained as $1.42 \mu \mathrm{m}$ in drill point angle of $140^{\circ}$, feed rate of $0.15 \mathrm{~mm} / \mathrm{rev}$ and cutting speed of $100 \mathrm{~m} / \mathrm{min}$. Lower cutting speed and feed rate are suggested for better surface roughness. The most important drilling parameter that effects the surface roughness is feed rate with a PCR of $78.02 \%$.

The highest hole size was measured as $5.07 \mathrm{~mm}$ in drill point angle of $120^{\circ}$, cutting speed of $140 \mathrm{~m} / \mathrm{min}$ and feed rate of $0.05 \mathrm{~mm} / \mathrm{rev}$. The lowest hole size was measured as $4.996 \mathrm{~mm}$ in drill point angle of $140^{\circ}$, cutting speed of $60 \mathrm{~m} / \mathrm{min}$ and feed rate of 0.15 $\mathrm{mm} / \mathrm{rev}$. This result can be explained with decreasing in tool-chip contact area due to increasing drill point angle.

This study is supported by Scientific Research Project Unit of Karabük University (KBÜ-BAP-15/2DR-022) and the authors express their appreciation for this support.

\section{References}

1. O. İsbilir, E. Ghassemieh, Compos Struct, 105, 126-133, (2013)

2. E.D. Eneyew, M. Ramulu, J of Materials Research and Techn, 3, 4 354-362 (2014)

3. O. Pecat, E. Brinksmeier, Procedia CIRP, 13, 1-7 (2014)

4. J. Xu, A. Mkaddem, M.E. Mansori, Compos Struct, 135, 316-338. (2016)

5. D. Liu, Y. Tang, W.L. Cong, Compos Struct, 94(4) 1265-1279 (2014)

6. I. Singh, N. Bhatnagar, P. Viswanath, Mater Design, 29(2), 546-553 (2008)

7. V. Krishnaraj, A. Prabukarthi, A. Ramanathan, N. Elanghovan, M.S. Kumar, R. Zitoune, J.P. Davim, Compos: Part B, 43, 1791-1799 (2012)

8. Y. Fan, L. Zhang, Advanced of Aircraft Manufacture Techn, 30(3), 534-543 (2009)

9. Jamal Y. Sheikh-Ahmad, Machining of Polymer Composites, (Springer, 2009)

10. A.M. Abrão, P.E. Faria, J.C.C. Rubio, P. Reis, J.P. Davim, J Mater Process Tech, 186(1-3), 1-7 (2007)

11. C.R. Dandekar, Y.C. Shin, J Manuf Sci E-T ASME, 130(5), 051016 (2008)

12. G.V.G. Rao, P. Mahajana, N. Bhatnagar, Compos Sci Techn, 67(3-4), 579-593 (2007)

13. J.L. Merino-Pérez, R. Royer, S. Ayvar-Soberanis, E. Merson, A. Hodzic, Composite Structures, 123, 161-168 (2015)

14. N.S. Mohan, S.M. Kulkarni, J Mater Process Tech, 186, 265-271 (2007)

15. S.R. Karnik, et al., Mater Design, 29, 1768-1776 (2008)

16. M.SenthilKumar, A. Prabukarthi, V. Krishnaraj, International Conference On Design And Manufacturing, IConDM, Procedia Engineering, 64, 582-592 (2013) 
17. I. El-Sonbaty, U.A. Khashaba, T. Machaly, Compos Struct, 63(3-4), 329-338 (2004)

18. O. İsbilir, E. Ghassemieh, Mach Sci Technol: An Int. Journal, 17(3) 380-409 (2013)

19. C.Y. Wang, Y.H. Chen, Q.L. An, X.J. Cai, W.W. Ming, M. Chen, International Journal of Precision Engineering And Manufacturing, 16(8) 1689-1697 (2015)

20. B. Latha, V.S. Senthilkumar, J Reinf Plast Comp, 28 951-964 (2009)

21. S.A. Ashrafi, P.W. Miller, K.M. Wandro, D. Kim, Materials 9, 828 (2016)

22. R. Rusinek, Int J Nonlinear Mech, 45, 458-462 (2010) 